\title{
REFORMA AGRÁRIA: O INCÔMODO DIÁLOGO
}

\section{REFORMA AGRARIA: EL DIÁLOGO INCÓMODO}

LAND REFORM: THE UNCOMFORTABLE DIALOGUE

\author{
Eliane Tomiasi Paulino \\ Professora Associada do Depto. de Geocências \\ Universidade Estadual de Londrina \\ eliane.tomiasi@uel.br
}

\begin{abstract}
Resumo: No seio da modernização técnica da agricultura a panacéia do desenvolvimento deu o tom da política das agências internacionais de fomento, tendo como alvo os Estados periféricos e como retórica o discurso do combate à fome. Desde então, uma série de fragilidades conjunturais tem sido elencadas para justificar os poucos avanços alcançados, não faltando promessas quanto a novas soluções técnicas que, no ciclo seguinte, tendem a culminar na mesma incapacidade de baní-la tanto quanto as vulnerabilidades que a provocam. A tese aqui defendida é a de que esse não é um problema tópico, como querem os governos e a diplomacia contemporânea, mas sim um problema estrutural, concernente ao modelo de acumulação, cujo ônus social e ambiental exige respostas distintas das correntes, até porque os resultados não justificam a manutenção das estratégias que vem sendo implementadas há quase meio século sem sucesso. Identificar seus limites e refletir sobre alternativas à agricultura, ao ambiente e à sociedade é a tarefa desse texto, tendo como fio condutor a análise das contradições dos discursos e práticas hegemônicas.
\end{abstract}

Palavras chave: Modernização técnica, desenvolvimento como retórica, apropriação produtivista da terra; apropriação especulativa da terra, soberania territorial

\begin{abstract}
In the agricultural modernization context a discourse was oriented to the international development efforts aimed at poor countries with hunger problems. Since then, the cyclical weakness has been used to justify the minimum hunger decrease with the promises that new technical solutions will solve them, but in the next cycle, tend to reinforce the same vulnerabilities. The thesis defended here is that this issue is not a temporary problem, according say governments and contemporary diplomacy, but rather a structural problem of the accumulation model, so society and environmental require new solutions, due to the fact the results no more justify to maintain the strategies that have been implemented for almost half a century without success. To reflect about limits and alternatives to agriculture, the environment and society we propose an analysis of the hegemonic discourses contradictions and practices from social classes.
\end{abstract}

Key words: Agricultural modernization, development as rhetoric, productivist land ownership; speculative land ownership, territorial sovereignty

Resumen: En el seio de la modernización técnica agrícola la panacea del desarrollo orienta la política de los organismos internacionales del desarrollo, dirigida a los paises afetados por el problema de la hambre. Desde entonces, la debilidad cíclica ha sido 
utilizada para justificar el escaso avance junto con las promesas de que las nuevas soluciones técnicas van a solucionarlos, pero en el próximo ciclo, tienden a reforzar las vulnerabilidades que lo causan. La tesis que se defiende aquí es que este tema no es un problema puntual, cómo quieren los gobiernos y diplomacia contemporánea, sino más bien un problema estructural del modelo de acumulación, cuya carga social y ambiental requiere respuestas diferentes de las corrientes, porque los resultados no justifican más el mantenimiento de las estrategias que se han implementado desde hace casi medio siglo sin éxito. Reflexionar sobre sus límites y alternativas a la agricultura, el medio ambiente y la sociedad es la tarea de este texto, que propone una análisis de las contradicciones de los discursos hegemónicos y de las prácticas de las classes sociales.

Palavras clave: modernización agrícola, el desarrollo como retórica, la propiedad productivista de la tierra ; la propiedad especulativa de la tierra, la soberanía territorial

\section{INTRODUÇÃO}

Embora os debates relativos à agricultura, em geral, e à propriedade privada da terra, em particular, tenham sido negligenciados nas últimas décadas, pelo alcance da crença de que o desenvolvimento seria o resultado necessário da mudança técnica subordinada ao processo de industrialização, é exatamente esse estágio que impõe a necessidade de se atentar aos processos que estão em curso no campo, porque na perspectiva territorial ambos formam um todo indissociável, não havendo dualidade nas relações de poder que soldam a unidade campo-cidade.

Da terra emana toda fonte de recursos indispensáveis à vida e, paradoxalmente, esses bens ocupam posição subalterna na lógica de preços que rege o circuito mundial das trocas mercantis. Isso não se deve à sua imprescindibilidade, antes à arquitetura global que por meio de expedientes coercitivos, científica, militar e politicamente falando, tem resultado em uma divisão do trabalho que há pelo menos meio milênio confere valoração desmesurada aos bens manufaturados e depreciação de bens primários.

Essa assimetria se explica pelo rígido controle sobre as fontes fornecedoras e potenciais de recursos, mesmo porque sem o abastecimento de matérias primas fartas e baratas o edifício da globalização ruiria num relance. A agricultura periférica é a que melhor expressa esse entrosamento coroado de subalternidade que, por sua vez, é produto da maneira com que cada região, em geral, e cada país, em particular, toma parte da divisão territorial do trabalho, cujo níveis de coerção e arbitrariedade determinarão o patamar de extração do excedente. 
As recentes investidas empreendidas tanto por Estados Nacionais quanto por grupos privados visando o controle de terras na África e na América Latina, seja para exploração imediata ou para reserva para uso futuro estão entre elas, situação em que a mera conformação territorial dos Estados segundo as fronteiras pouco tem a ver com o exercício de poder como concebido pela geopolítica clássica. A essa escapa o fato de que embora o Estado-Nação seja o único mandatário no que concerne às relações que transcendem os marcos fronteiriços, não raro marcadas pelo conflito, isso não significa que tal investidura tenha sido soldada na unanimidade interna. Antes, o Estado é o instrumento por meio do qual se exercem hegemonias que, por sua vez, emergem no seio das relações de poder impulsionadas pela tentativa de controle de recursos distribuídos num vasto leque de possibilidades, mas que assim o são porque de alguma forma se apresentam como trunfo.

Por essa razão, a geopolítica é o exercício da negociação política entre hegemonias que se definem no plano da luta de classes. Por isso o saldo é assimétrico para os Estado-Nações sem deixar de proporcionar vantagens compartilhadas entre os atores hegemônicos devidadamente representados por eles. Sendo assim, a entrada de estrangeiros em solo pátrio, na condição de proprietários, não tem sido motivo de rupturas ou sanções porque isso lhes está favorecendo, por mais que aos demais cidadãos possa ser nocivo.

Compreender a razão pela qual os sujeitos que referendam essa apropriação são os mesmos que combatem ferozmente o acesso ao solo pátrio por concidadãos requer atenção para os desdobramentos de tais inversões estrangeiras. Elas podem proporcionar o aquecimento do mercado de terras, leia-se, o aumento geral dos preços, a taxas que internamente eles não poderiam fazê-lo. Como é precisamente o mercado de terras que institui a renda capitalizada, quanto maior for a demanda, mais eles poderão se locupletar. O regime de monopólio comparece como vantagem adicional, também traduzida em cifras.

O ocultamento dessa lógica se manifesta nas investidas para que a sociedade se convença de que a reforma agrária e a garantia dos territórios das populações tradicionais seriam nocivas às economias nacionais, sendo possível agrupar em dois grandes grupos os argumentos, os que advogam seu potencial destrutivo do ponto de vista da economia agrícola, por supostamente restringirem a capacidade de expansão da produção, e os que vislumbram a sua inocuidade, que decorreria do retardo das medidas ante a atual dinâmica social. 
O primeiro é o mais redundante e factível no plano do senso comum, povoando o discurso da classe proprietária e de seus partidários ocupados em forjar púlpitos em toda parte, da mídia à escola. A retórica do segundo é mais elaborada, compatível com o lugar de onde é disseminado, a ciência, especificamente aquela que se pretende neutra, por isso o desdém aos propósitos que obstruem o circuito da renda capitalizada da terra em nome de uma racionalidade e eficiência a ser posta em questão. Refletir sobre os interstícios do veto ao desenvolvimento como emancipação e não como retórica, sem perder de vista papeis e posições políticas que se definem no contexto dos enfrentamentos teóricos e nas alianças de classe é o que aqui se propõe.

\section{A PROPRIEDADE PRIVADA DA TERRA COMO ALIADA DO PROCESSO DE ACUMULAÇÃO}

O conteúdo de classe é determinante no jogo de cena em que a terra parece ser prescindível, e precisa parecer que é, porque poucos podem se beneficiar do circuito que a torna mercadoria, embora ela seja um bem essencial e insubstituível. Além de sua condição de substrato material inalienável, é a fonte dos recursos que se transformam em matérias primas e dos alimentos convertidos em commodities. $\mathrm{O}$ resultado dessa trama é a secessão e a exclusão, que mais que qualquer outro fator respondem pela pobreza que se manifesta com particular intensidade no campo: de acordo com a FAO (2012), 75\% dos pobres do planeta atualmente vivem em áreas rurais da periferia do sistema capitalista.

Por essa razão, o debate sobre as interdições à terra de trabalho pode começar pela releitura do tema da estrangeirização das terras que, à primeira vista, sugere uma dinâmica fundada exclusivamente em vetores externos, sobre os quais seria muito difícil exercer o devido controle, fenômeno esse conhecido como acaparamento de terras. Como lembram Borras e Franco (2012, p. 2), isso é insuficiente para explicar as investidas atuais sobre as terras camponesas e das populações tradicionais, uma vez que se há Estados ou empresas do hemisfério norte os expulsando, isso se deve à anuência dos governos e classes dominantes locais, para os quais não deixa de ser conveniente essa mistificação que, ao fim, os isenta da pilhagem da qual se beneficiam, quando não são eles próprios que as perpetram.

Sendo assim, os autores sugerem a mudança do foco, incorporando-se um conceito mais abrangente, soberania territorial, o qual permite evocar a divisão 
equânime da terra, cujas implicações são qualitativamente distintas da abstrata noção de pertencimento que as fronteiras nacionais supõem. Concordar com esse conceito significa referendar os direitos territoriais das populações nativas, tradicionais e camponesas, que tem sido vitimadas pelo esbulho consentido pelo pacto hegemônico do país ao qual pertencem.

Se esse é um processo de longa data, o mesmo não pode ser dito da retórica do desenvolvimento, que emergiu juntamente com as mudanças técnicas dessa última metade de século. Ao transformarem as possibilidades de uso da terra pela inédita via da eficiência fundada na relação inversamente proporcional entre escala e composição de trabalho vivo, intensificada a cada ciclo de incremento tecnológico, requer igual sofisticação dos mecanismos ideológicos de estímulo à adesão incondicional e, paralelamente, os de acobertamento do seu caráter vulnerabilizante, social e ambientalmente falando.

De acordo com Mazoyer e Roudart (2010, p. 27), a diferença de produtividade entre lavouras com tecnificação máxima e ausência dela no final do século passado já chegava a 2.000 vezes. Isso dá algumas mostras de como se desencadeia o processo de exclusão, em que se combinam monopolização da terra, cujas operações requerem elevada escala como forma de redução proporcional dos custos, de um lado, e logística cujo comando provém do capital industrial, comercial e financeiro, que opera mediante a remuneração baseada em taxas de lucro médias. O desajuste nos mecanismos de acesso à terra é a necessária implicação dessa lógica, pois quanto mais eficiente e atrativa for a atividade agrícola, mais áreas deverão ingressar no circuito em caráter de monopólio.

Ocorre que esse é um bem irreprodutível, o que já seria suficiente para aumentar a disputa pela utilização intensiva mediante elevados índices de investimento, em prejuízo da agricultura camponesa, cuja eficiência não pode ser medida por tais parâmetros. Ocorre que essa não é a única pressão sobre as terras de trabalho, que cada vez mais estão acossadas pela especulação, cujo cerco se manifesta em imensas áreas improdutivas, mantidas como reserva patrimonial ou de valor. É precisamente essas nuances que a ortodoxia econômica tem ignorado, já que elas são condicionadas e condicionantes da renda capitalizada, dada a modalidade de enriquecimento automático e seguro que o desequilíbrio na oferta de terras proporciona.

Em outras palavras, manter o controle sobre áreas que somente são improdutivas porque sob a ótica dos proprietários isso é mais compensador do que colocá-las para 
produzir é apenas um indicativo de que a distorção no mecanismo de oferta de terras se acentua ao mesmo ritmo do movimento de capitais em direção ao setor da agricultura, seja ele produtivo ou especulativo. Identificar tais mecanismos é fundamental para escapar ao embuste do desenvolvimento tal qual ele tem sido proposto, porque o negligenciamento desses fatos depõe contra uma reflexão crítica e fundadora de outras bases para o projeto societário que tem no presente as possibilidades de contrução.

Em primeiro lugar, é necessário que se reafirme que a terra não é um meio de produção igual aos demais, como faz crer a ortodoxia que contagia a ciência e a política. Dentre os meios de produção, ela é a única que comporta a ociosidade rentável, e atualmente há mais terras nessa condição do que sendo cultivadas, especialmente nos países em que não foram implementadas e ou mantidas políticas de reordenamento fundiário, sendo justamente nesses que a pobreza rural se manifesta com maior veemência.

O caso brasileiro é um bom indicativo disso, uma vez que os conflitos por terra frequentemente são interpretados como se fossem motivados pela disputa em torno de quem vai usá-la, quando seria mais apropriado observar também se e como ela vai ser utilizada. Se tomarmos os dados da CONAB (2012), conclui-se que menos de $8 \%$ da área agricultável do país foi semeada na última safra, devidamente descontadas as terras indígenas, unidades de conservação e usos não agrícolas. Esse dado é muito próximo do cálculo divulgado pelo Banco Mundial (2010), para o qual esse percentual seria de $8,1 \%$. Nos quatro países que estão à frente do Brasil no valor das exportações agrícolas, respectivamente Estados Unidos, Holanda, Alemanha e França, o percentual do território semeado é incomparavelmente superior. Nos Estados Unidos a área semeada está aferida em 18,1\%, na Holanda em 32,2\%, na Alemanha em 34,9\% e na França em $35,4 \%$. (FAO, 2010).

O fato de a densidade populacional bem como os padrões de cultivo na Europa não serem um bom parâmetro nos leva a observar mais de perto o caso estadunidense, pois neste a relação entre área cultivada e valor exportado é de 1,4 dólares, enquanto no Brasil ela é de 1,2 dólares. Essa diferença é irrelevante se consideramos o gradiente de desigualdades no interior da agricutura brasileira em relação à estadunidense, o que permite afirmar que a diferença da receita com exportações entre ambos se deve fundamentalmente à quantidade de terras utilizadas produtivamente. Vale lembrar que a receita das exportações agrícolas do Brasil correspondem a apenas 48,8\% da dos EUA, embora não haja variáveis de natureza topográfica, edafoclimática, tributária, creditícia, 
fundiária e de escala que expliquem a diferença de percentuais, uma vez que estamos falando de commodities, com preço unificado no mercado mundial. Pode-se então concluir que a manutenção da terra com fins especulativos pode ser até mais atraente do que a inserção no mercado de commodities, cuja lucratividade não é desprezível, e a sua expansão o revela.

Guardadas as devidas distinções e proporcionalidades, essa regra se aplica onde quer que os mecanismos institucionais sejam flácidos o suficiente para imputar quaisquer limites à rapinagem que move o capital. Se no campo ela se oculta na vitalidade da atividade de escala altamente tecnificada, ao preço de um passivo social e ambiental que está longe de ser contido, também está resguardada pelas cercas da propriedade privada que viola o princípio da função social em todos os aspectos.

A luta coordenada para obstruir a democratização do acesso à terra, ao preço da impunidade ao latifúndio é a mais clara evidência da aliança de classes: não fosse isso, a fratura emergeria, como já aconteceu nos primórdios da revolução burguesa, momento em que os próprios capitalistas se encarregaram de forçar a utilização produtiva das terras, daí o sentido da reforma agrária como estratégia utilizada em seu favor, mas que obviamente se refletiu em benefícios para aquelas sociedades.

Ocorre que no transcorrer de pouco mais de um século, o ritmo de produção de mercadorias cresceu exponencialmente, o que mantém uma equivalência com a demanda por matérias primas, logo pela base material de ondem elas provém. Por mais que se saiba que o pacote técnico dá o tom da dinâmica da renda diferencial II no campo, em que as diferenças de rendimento agrícola são determinadas pela intensidade dos investimentos, ele não tem como intervir nos mecanismos constituintes da renda diferencial I, que deriva primeiro da natureza e, segundo, da dinâmica geral da sociedade. Como o processo de valorização que funda a renda capitalizada da terra se mede pela relação inversamente proporcional entre investimento e lucro, o processo de monopolização associado à lógica rentista cada vez será mais ameaçador aos pobres do campo e à sociedade em geral, porque quanto mais aumentar a demanda por alimentos e similares, mais terras aptas a proporcionar renda diferencial I serão alvo de negócio.

Essas terras são aquelas bem localizadas em relação ao mercado, dentre as quais estão muitos dos produtores que não tem escala de produção para tomar parte do mercado global. São também aquelas mais férteis, como o são as cobertas por vegetação nativa ou ocupadas por populações autóctones. Assim se desenha a tendência de aprofundamento dos impactos socioambientais desdenhados pelos que em nome da 
segurança alimentar continuam enamorados da tecnologia de ponta e do mercado globalizado, que por tudo isso é incapaz de promover a racionalização virtuosa no campo.

O aumento generalizado dos preços da terra (GASQUES; BASTOS; VALDES, 2008; USDA, 2011) tem dificultado cada vez mais a recriação do campesinato dentro do circuito fundiário mercantilizado, porque o aumento da escala é um imperativo do processo de modernização, e para essa classe isso somente seria possível mediante a ampliação das propriedades. Nesse sentido, a inconsistência das soluções ortodoxas é flagrante, porque o seu sentido último é a negação da pertinência das políticas públicas de reordenamento fundiário, enquanto é precisamente aí que começa a solução de seu problema.

De acordo com a FAO (2012, p. 7), em 1980 o percentual de pobres entre a população rural da América Latina era de 60\%, ao passo que em 2010 atingia 53\%, uma evidência de que se no passado a situação era fruto do latifúndio, atualmente a empresa rural produtiva e a empresa rural rentista, caso se considere o conceito de latifúndio inapropriado, são co-responsáveis, restando portanto uma alternativa: a justa distribuição da terra. Diante desses dados, o argumento de que a Reforma Agrária é uma bandeira preterida pelo curso da história, por força da mudança dos padrões produtivos e societários não encaixa. Se há algo que os números permitem afirmar que a história se encarregou de remover, diríamos que é o verniz que em nome da ciência serve para dissimular os posicionamentos de classe.

Reafirma-se, assim, que visceral à pobreza rural não é o estágio técnico na agricultura e tampouco o grau de inserção no mercado, ainda que isso seja verdadeiro em alguma medida. Isso é secundário ante um fator estrutural precedente, a insuficiência de terras, reafirmada pela burgoligarquia que se constituiu na periferia do sistema capitalista ao ritmo da modernização técnica. Longe de insinuar a diluição do conceito de classes, esse termo expressa a sobreposição típica do capitalismo rentista, em que parte da burguesia tem negócios fundiários do mesmo modo que parte dos proprietários tem empreendimentos capitalistas, sendo importante lembrar que no mundo dos negócios se há algo que não se preza são as fronteiras. Por isso, não raro o produto da rapina social, leia-se renda da terra, flui para as mesmas mãos dos que se apropriam diretamente da mais valia individual. Ambas constituem uma indivisível riqueza que assim integra o processo de acumulação ampliada. 
Ao debruçar-se sobre o caso brasileiro, Oliveira (2010) constatou que a burguesia vinculada ao agronegócio se constituiu por meio de ampla rapina territorial, valendo-se da grilagem para apropriar-se das terras públicas, uma evidência de que os capitalistas também recorrem a práticas alheias aos cânones que dizem ser sagrados, os mecanismos de mercado fundados na compra e venda de terras. Ademais, ao debruçarse sobre os dados oficiais relativos à situação jurídica da terra no país, concluiu que esse expediente tanto está na raiz da constituição da propriedade privada quanto é produto da ação ativa ou passiva do Estado, que nem sempre fez distinção de origem, entre nacional e estrangeiro, embora nunca tenha abdicado da prática de favorecimentos que está na raiz da questão agrária.

A promiscuidade entre as práticas aceitas como legítimas e as que supostamente foram banidas da moderna economia capitalista foram denunciadas por Harvey (2004), que identificou no que denomina de acumulação por espoliação os mecanismos de conversão de bens públicos em recursos privados, cuja implicação primária é o alijamento de seus legítimos usufrutuários, as populações locais.

Por essa razão, concordamos com Oliveira (2010), quando adverte ser improcedente o temor pela estrangeiração das terras no Brasil, o que para ele seria um factóide, um recurso de comunicação utilizado pelo próprio governo cujo fim é a disseminação de falsas verdades para que a sociedade tenha a atenção desviada de problemas reais. No caso em questão, entende que ameaça maior, porque proporcionalmente mais impactante, é a grilagem, o monopólio fundiário e o assalto aos cofres públicos, amplamente praticados por compatriotas, embora também o seja por estrangeiros. Por essa razão, o que deve ser extirpado são tais práticas, independentemente de quem as perpetre, e isso somente se faria com a adesão a um projeto de soberania territorial, que antes de mais nada supõe equidade na partilha dos recursos, a começar pela terra, daí a imprescindibilidade da reforma agrária (BORRAS, 2011, p. 212).

Ocorre que essa atenta contra os negócios fundiários, por sua capacidade de neutralizar o processo de valorização forjado pelo monopólio, uma vez que não há qualquer trabalho na constituição da terra. Desse modo, o preço de mercado é determinado exclusivamente pela relação de oferta e de procura, e quanto mais monopolizada ela for, mais renda capitalizada poderá proporcionar, com o agravante de que a diferença dos demais meios de produção, é irreprodutível e indispensável. Por isso, discordamos de Bernstein (2012), que afirma não ser a terra, mas sim o trabalho 
que está no centro da questão agrária, daí o argumento de que camponês deixou de ser uma categoria útil de análise. De acordo com essa linha de raciocínio, o campo seria o palco da luta entre capital e trabalho, sendo o restante residual ou secundário, inclusive a terra.

O limite dessa sentença parece repousar na dualidade que necessariamente impõe hierarquizações inaplicáveis se considerarmos a interpretação de Marx (1974), que vislumbrou na terra e no trabalho as duas únicas e indissociáveis fontes de riqueza, uma vez que tanto uma quanto o outro nada representam isoladamente, sendo necessário o concurso de ambos para criá-la. Aliás, os meios de produção virtuais ou reais que hoje mobilizam cifras colossais procedem daí e não os prescindirão jamais, por mais que pareçam estar descolados dessa materialidade. Desse modo, a atenção deve recair sobre os contextos sociopolíticos no interior dos quais emanam as decisões de como gerir a base de recursos e eles próprios, porque isso antecede à definição de escalas e de fronteiras. Somente eles podem fornecer pistas para entender o sentido dos projetos territoriais expressos em políticas de desenvolvimento e distintos arranjos do ponto de vista ambiental e social.

Segundo Veltemeyer (2011a), o ideário do desenvolvimento, materializado no projeto de modernização agrícola, foi instituído em resposta às aspirações e mobilizações por reforma agrária presentes em toda a periferia do sistema capitalista, uma vez que o colonialismo nada mais foi do que a usurpação de terras e de bens a ela vinculados. Em essência, essa concepção de desenvolvimento é portadora de um significado que se opõe ao protagonismo dos movimentos sociais, de modo que os programas e as ações dos mediadores incumbidos de implementá-los são desmobilizadores o suficiente para minar as possibilidades de autonomia que poderiam florescer no seio das organizações populares.

Ademais, a orientação conservadora dos mentores do desenvolvimento rural se revela por sua própria vinculação: a conferência monetária das Nações Unidas onde foi instituído o acordo de Bretton Woods, o marco regulatório das novas formas de acumulação do capital desde meados do século passado.

Como resposta à profunda crise de acumulação, ele veio embalado por um conjunto de estratégias de legitimação da ordem capitalista, sendo papel do ideário do desenvolvimento rural favorecer a ampliação do circuito mercantil sem minar a esperança em dias melhores; no contexto em que o socialismo se apresentava como uma saída possível, essa era uma condição imperiosa para o afastamento dos riscos de uma 
revolução. É por isso que o autor afirma que essa foi a terceira via do consenso, porque preconizado como alternativa ao colonialismo e, ao mesmo, tempo, à revolução social. Seus limites não poderiam ser mais explícitos.

\section{TERRA E VIDA NO JOGO DA ACUMULAÇÃO E DAS ALIANÇAS DE CLASSE}

A concentração do uso da terra oportunizada pela mudança técnica e pela progressiva exclusão que o imperativo do mercado global impõe se deu dentro de um contexto de vulnerabilização não apenas do modo camponês de produzir no campo, pois a fragilização dos ecossistemas em escala planetária se deu ao mesmo ritmo, o que denuncia a complexidade dos vínculos para tudo convirja para a acumulação de capital em escala ampliada, em cujo centro está a mercadoria, essa instituição que adquire feições tão diversas que é impossível enumerá-las, mediante as quais a mais valia se realiza. Para isso, a geografia dos lugares é determinante, porque a ocorrência dos bens passíveis de uso comercial não se define pelas forças do mercado, mas sim pelas da natureza, sendo as formas e o ritmo de apropriação uma equação determinante e determinada pelo valor de troca inerente aos recursos aí existentes bem como o seu lugar na divisão territorial do trabalho. Ocorre que nessa ciranda prevalece o imperativo da transformação cada vez mais acelerada de bens naturais em mercadorias, por intermédio da única força criativa possível, o trabalho humano.

Não por acaso, os princípios contemplados em planos de desenvolvimento gestados no interior de organismos multilaterais, em regra reiterados, no plano do discurso, pelos governos nacionais em quaisquer instâncias político-administrativas internas, centram o foco em duas frentes básicas de ação, bem estar social e sustentabilidade ambiental. Essa projeção revela que esses são os aspectos mais proeminentes no conjunto das contradições geradas no bojo das relações de produção, visto que o trabalho e os bens gratuitos da natureza passíveis de serem convertidos em valores de uso, esses dois pilares não só do presente mas inclusive do devir, estão sendo desdenhados no contrato societário instituído em nome da racionalidade do mercado, a ponto de inviabilizar um horizonte civilizacional longevo.

Desse modo, no que refere-se à gestão territorial, a difícil conciliação entre o proposto e o executado revela que o Estado nacional é a instância primaz de mediação, e isso vale tanto para o plano interno quanto para as relações internacionais. Entretanto, 
longe de estar posicionado de modo a zelar pelo bem comum, encontra-se apropriado pelas forças que conjuntural ou estruturalmente são hegemônicas em cada país, e que estão alinhadas a partir de uma perspectiva de classe e seu lugar no mundo da produção.

A melhor maneira de reconhecê-las fora ensinada por Marx (1974): a origem do rendimento dos indivíduos, que tanto pode ser do trabalho transferido a outrem mediante um salário, do lucro obtido na operação inversa a essa, da tributação social extraordinária que a condição de proprietário privado de solo urbano ou rural permite ou, por fim, da condição sui generis do campesinato, que articula propriedade dos meios de produção e força de trabalho. Essa constituição não é pura, estática e tampouco, refratária, pois como ensinou Shanin (2008), classe é uma abstração, o que não significa que seja uma definição vaga, mas que na realidade ela dificilmente poderá ser encontrada em estado puro, e isso vale para as demais, o que explica a existência de contradições inconciliáveis mas também a possibilidade de convergência de interesses parciais e inclusive de determinadas alianças.

Para isso conta mais aquilo que converge do que aquilo que distingue: Lênin (1980), ao eleger a propriedade da terra como elemento de distinção, entendeu que os camponeses tinham mais interesses em comum com os grandes proprietários do que com os trabalhadores, daí classificá-los de pequenos agraristas. A história o contestaria. Por sua vez, Kautsky (1980) viu nessa mesma propriedade camponesa da terra o único meio capaz de proporcionar a sobrevivênciada da família, tanto quanto os empregos representam para os trabalhadores expropriados. Portanto, o elemento de convergência em sua análise é o trabalho, e isso os aproxima.

No contexto da crítica ao conceito de desenvolvimento condicionado à industrialização, em que a agricultura deveria comparecer como subsidiária, Kay (2009, p. 105, 106) identifica a convergência de interesses que explica a manutenção da hegemonia compartilhada entre proprietários fundiários e industriais. Segundo ele, para delinear os programas de desenvolvimento rural, em que a indagação implícita era como a agricultura poderia ajudar ou atrapalhar o desenvolvimento, havia duas escolhas possíveis: a reforma agrária, como forma de ampliação da produção a um ritmo capaz de abastecer a indústria de matérias primas e fomentar a constituição do mercado interno ou o caminho da produção de escala baseado no monopólio fundiário. Nesse sentido, mostra como as possibilidades de apropriação do excedente de riqueza pelos agentes do capital e da propriedade privada da terra criaram a inusitada aliança. 
While there are some divergent interests between landlords and industrialists these are minor compared to the class conflicts between capitalists and workers. Landlords often invested in urban enterprises and urban capitalists acquired landed properties, generally for social prestige and political reasons, thereby facilitating the formation of alliances between them. [...] Through forging alliances and common interests landlords and urban capitalists resolved some of the contradictions between these different fractions of capital so as maintain their dominance over the exploited classes in society. (KAY, 2009, p. 113)

Esse é o sentido da aliança proveniente da convergência de interesses de classe mencionadas. Não sem razão, Akram-Lodhi, Kay e Borras (2007) discordam das abordagens que colocam no centro da questão agrária a relação entre o capital e o trabalho, como o faz Bernstein (2012). Ao invés disso, entendem que é a terra, ou melhor, o controle sobre ela é que é central para a análise da questão agrária, a qual deve revelar como se dá e quais são os propósitos desse controle.

Nesses termos, o que convém aos proprietários capitalistas da terra e aos demais capitalistas atenta contra os interesses dos camponeses e dos demais trabalhadores, porque são eles que extraem mais valia, diretamente, por meio das relações de assalariamento e indiretamente, por meio do auferimento da riqueza social via tributação extraordinária, a renda da terra, que é também sacada dos camponeses, por diferentes mecanismos de sujeição. Distinguir tais agentes nem sempre é possível, uma vez que proprietários capitalistas da terra eventualmente são industriais, banqueiros, grandes comerciantes, sendo a recíproca verdadeira, pois cada vez mais a diversificação dos negócios passa a ser uma estratégia importante para a blindagem contra os riscos. Por definição, nos confrontos de classe seus oponentes são os camponeses e os trabalhadores que, por sua vez, travam lutas distintas, sem que isso signifique estar em outra trincheira.

Desse modo, as duas classes que compõem o bloco hegemônico da sociedade, os proprietários capitalistas da terra e os proprietários capitalistas dos demais meios de produção, dividem entre si a riqueza excedente, o que não significa que seja aquela que sobra, mas sim a que é extraída às expensas de condições mínimas de existência de seus produtores imediatos. Não convém omitir também a riqueza extraída antecipadamente das gerações vindouras, que virão a um mundo marcado por um débito acumulado em passivo ambiental, a ser inevitavelmente saldado, seja com gasto ampliado de energia vital, porque o labor no necessário intercâmbio com a natureza para o provimento das necessidades inalienáveis se dará em condições mais desvantajosas que as atuais, seja 
com a vida em sentido estrito, onde e quando esta for abreviada pela ausência do mínimo indispensável, como água potável e alimento e todas as violências que isso impõe.

Ao debruçar-se sobre a situação do México, Treteault (2012) concluiu que o desmatamento atinge uma cifra anual que varia entre 316 e 800 mil hectares por ano, ritmo que mantém relação estreita com os processos erosivos que já atingem $45 \%$ do território nacional. Nesse país onde em determinadas regiões a escassez hídrica chega a ser severa, estima-se que 100 aquíferos já se encontram sobreexplorados, colocando para um cenário próxima a inviabilização do abastecimento em muitas cidades, a exemplo de Zacatecas, onde a interrupção do fornecimento tornou-se uma rotina cada vez mais abreviada.

Contudo, o autor mostra que os impactos não são democraticamente distribuídos, pois os camponeses, os indígenas e as populações mais pobres das franjas urbanas são as maiores vítimas da degradação ambiental. Por isso, assevera que as recorrentes manifestações não raro tratadas como eventos isolados são lutas por recursos vitais apropriados por grandes proprietários e empresas que os tem como mercadoria e não como bem para o usufruto.

Em suma, a coalisão de interesses de classes tem sido capaz de colocar no plano secundário diferenças intrínsecas, a exemplo da perpetuação do tributo materializado na renda da terra, que se num primeiro momento resistiu ao modo capitalista de produção em vista da necessidade da própria burguesia de legitimação do direito de propriedade, evoluiria para um estágio em que ao invés de ser tolerada, torna-se instrumento de acumulação por meio do viés rentista, o mesmo que está na raiz da financeirização da economia, cujo potencial desestabilizador apenas começa a ser sentido, visto que especular tornou-se um dos mais lucrativos negócios na atualidade e isso não se restringe mais à terra.

Sendo assim, em comum ou por referendo, todo e qualquer mecanismo institucional que possa perpetuar supremacias será utilizado, e toda oposição será combatida, sendo a repressão social e a violência a estratégia derradeira, quando não há mais espaço para mediações, pois como lembrou Arendt (2009), uma evidência de perda de legitimidade no exercício do poder é o uso da força. Por isso, ao prevalecer o imperativo da acumulação ampliada de capital, toda proposta de gestão transformadora será rechaçada ou amputada, convertendo-se na melhor das hipóteses em paliativos que não tem como modificar os processos estruturais, pois estes estão constituídos pelas 
engrenagens vorazes da acumulação ampliada, cuja força destrutiva não admite desdém, como defende Bartra (2008).

Contudo, essa problemática não comporta abordagens estruturalistas, como se se tratasse de um processo de mão única, pois isso seria o mesmo que negar o mais básico princípio da dialética, a contradição, que invariavelmente se manifesta na complexa dinâmica do exercício do poder, em que se confrontam resistência, combate e adesão aos ditames do capital. Reconhecer a sua hegemonia, dadas as relações assimétricas travadas no seio da sociedade no processo de produção material e reproducão social, não é o mesmo que cair na armadilha abstracionista que a confunde com homogeneidade, porque é precisamente na dissidência que é possível construir caminhos para a sua superação.

Essa é a síntese que se materializa na territorialização distintiva com que se apresentam os países, sendo os rótulos correntes que os opõem entre ricos e pobres, desenvolvidos e subdesenvolvidos, um desserviço à superação destas contradições, porque em seu interior há múltiplas dimensões de poder e, consequentemente, múltiplas territorialidades em movimento, por força dos embates de classe.

Por isso, não se equivocara Costa (2008) ao afirmar que os Estados Nacionais nada mais foram do que as fronteiras instituídas por grupos hegemônicos locais como forma de assegurar para si uma base de recursos considerada imprescindível para sua perpetuação. Chesnais (2012) compartilha da mesma assertiva, ao analisar a polêmica gerada pelo caso WikiLeaks, para o qual a máquina do Estado funciona mais para a blindagem desse em relação à população do que propriamente como instrumento de mediação e administração de conflitos no plano externo. Andrade (1989) já o havia anunciado.

Eis a razão pela qual o desvendamento da composição de classes e do seu respectivo gradiente de forças é fundamental para se compreender os impasses ora colocados, em termos ambientais e sociais. Da mesma maneira, é um instrumento analítico que permite refletir sobre algumas das teses mais repetidas acerca da globalização, em particular, a que prescreve a impotência dos Estados Nacionais ante o poderio das corporações transnacionais.

Embora não se possa negar a sua notável fluidez territorial, produto de uma superioridade econômica e técnica, por vezes superior a de alguns países, não deixa de ser simplismo, para não dizer conivência oportunista, valer-se dessa leitura para explicar 
tratados, acordos, programas e concessões que, em nome do desenvolvimento, acentua a vulnerabilidade dos pobres.

O fato é que somente os Estados Nacionais dispõem da prerrogativa de gerir a base de recursos aprisionada em suas fronteiras e no seio da ordem neoliberal o fazem por meio da instituição de normas legais para a ação privada, os marcos regulatórios em torno dos quais se dão as principais disputas. Elas se expressam de diferentes maneiras, como em pautas político-partidárias, de associações classistas, de movimentos sociais, afora aquelas que se definem não no palco, mas nos bastidores da política.

Nesse confronto, a transcendência de classe em relação às fronteiras nacionais se explicita: a ação de grupos estrangeiros em solo pátrio depende da autorização do Estado, e quando esse a concede, o faz em prejuízo dos interesses nacionais, a exemplo das concessões de mineração, de exploração de recursos hídricos e de vastas áreas de florestas ou terras cultiváveis interditadas à população local. Isso convém aos interesses dos que internamente detém a hegemonia, logo sustentam o governo, e isso obviamente não se resume aos postos ocupados na estrutura político-administrativa do aparato estatal. Aí se poderá vislumbrar o alinhamento que não se define pela posição territorial, a nacionalidade, mas sim aquele advindo da unidade de classe.

A mudança do Código Florestal Brasileiro é uma evidência disso, pois a já frágil margem de controle social sobre o uso da terra e dos recursos naturais do país foi enfraquecida pelo protagonismo do pacto rentista, produto da aliança entre terra e capital que, aliás, é a indutora das assimetrias na divisão da terra e do fundo público para o fomento da agricultura. Não custa lembrar que isso se deu em nome dos camponeses, os que menos tem a ganhar com a mudança, visto que essa ela sanciona aquilo que mais os tem ameaçado, as práticas rentistas. Como visto, sob esse império o que dá o tom da apropriação privada da terra é o monopólio produtivista e também o estéril controle especulativo, o oposto do que se poderia esperar segundo os parâmetros econômicos e mesmo teóricos mais disseminados.

Esse é o detalhe que escapa aos teóricos que seguem analisando a terra como um meio de produção semelhante aos demais, quando na verdade ela é equivalente de capital, dado que aí a riqueza flui por duas vias, a produção, quando há, e a renda, mesmo que não haja. Esse é o seu diferencial, que implica em açambarcamento da riqueza social sem necessariamente nenhuma intervenção direta: o direito de propriedade é chancela suficiente para o saque. 
Por isso, a fúria açambarcadora sobre as terras camponesas, indígenas e das demais populações tradicionais em escala planetária. A Cúpula dos Povos, o evento que ocorreu paralelamente à, Conferência das Nações Unidas sobre Desenvolvimento Sustentável (Rio + 20), deu uma mostra do denominador comum dessas lutas, muitas vezes desconhecidas, graças à eficiência do pacto que produz e distorce verdades segundo as conveniências dos atores hegemônicos da sociedade.

Ainda que os bens primários sejam extremamente desvalorizados, carecendo da agregação de valor que atualmente está sob controle de um número reduzido de corporações transnacionais, a monopolização da terra é fator de locupletação, inclusive porque além da renda, dela são extraídos bens como madeira, minérios e afins, os quais são imediatamente convertidos em mercadorias indispensáveis ao circuito do capital.

Em tempos de apetites vorazes por terras, água, árvores, minerais e mais uma inumerável lista de bens da natureza privatizáveis, essas considerações são importantes para delinear o foco das lutas sociais, em particular as camponesas, que na atualidade propõem a bandeira, por meio da Via Campesina, de uma soberania alicerçada em cinco dimensões: alimentar, energética, genética, hídrica e territorial, umbilicalmente atreladas à terra.

Assim, há que se escapar da sutil armadilha ao imobilismo que emana das teses que ignoram o conteúdo de classe oculto nas disputas por recursos que não existem fora da terra, bem como pela singular mercadoria trabalho, os pilares da produção em quaisquer escalas que se queira considerar, de um município a um continente.

A despeito da complexa dinâmica de funcionamento do modo de produção capitalista, em essência nada há de novo ao que Marx pontuou para a identificação dos seus elementos chave, que consiste no intercâmbio dos seres humanos entre si e com a natureza para o provimento de suas necessidades vitais, sejam elas reais e ou fictícias.

Em tempos de crise social e ambiental profunda, em que bens inalienáveis são dilapidados por força da ordem hegemônica que os trata como se fossem reprodutíveis ou infindáveis, um devir possível requer outro projeto societário, o qual não virá senão por meio de um amplo reposicionamento ante a noção de desenvolvimento, capaz de romper com a representação da fábrica e o fetiche da produção mágica. Antes, trata-se de construir um conceito de sustentabilidade onde a parcimônia tenha lugar, a qual é irreconciliável com a lógica da acumulação ampliada, que ao mesmo tempo em que aprisiona poucos no imperativo do consumo irrefreável, suga da maioria o excedente que a alimentará. 


\section{CONSIDERAÇÕES FINAIS}

A tese aqui defendida é que a questão agrária não diz respeito tão somente à agricultura e ao campesinato, antes segue como elemento substancial do processo de acumulação de capital, daí a sua centralidade na atualidade. Isso requer $o$ posicionamento ante os estudos do campesinato, cujo suposto desaparecimento segue alimentando os debates, como se pode verificar em Ellis (1998), Bernstein (2012), entre outros que, no essencial, mantém viva a sentença de Kautsky (1980), proferida no final do século XIX.

Ao invés de adentrar na teia dos argumentos, o que demandaria um exercício à parte, parece mais oportuno deixar a realidade falar, a qual revela a sua presença incômoda, e o fato de eles continuarem em pauta mesmo pretensamente sem existir ou ter chances de fazê-lo doravante fala por si. Essa condição é que vem perturbando muitos dos esquemas de interpretação, tal qual mostrou Huizer (2001, p. 164), para o qual essa tendência se desdobra em duas correntes, a que os toma como passíveis, pacatos, incapazes de construir um destino político por sua aparente incapacidade de organização política e a que os classifica de fanáticos e irracionais, sempre que irrompem em lutas contra os usurpadores de sua terra de trabalho, sejam proprietários, comerciantes, agiotas, burocratas e outros mais.

O fato é que a resiliência desses sujeitos está repleta de significados, pois como disse Shanin (2008), eles tem mais a nos ensinar do que seríamos capazes de lhes retribuir, até porque a construção de um mundo sustentável, social e ambientalmente falando, passa por suas mãos, razão pela qual eles estão menos para lastro do passado do que reserva para o futuro.

Embora não se possa desdenhar a força desagregadora das investidas hegemônicas, também não se deve minimizar seu potencial criativo e criador, que tanto desafia a teoria, a política e a economia. A teoria porque não foram poucos os que preconizaram o seu desaparecimento e seguem fazendo-no, daí a sua presença discreta ou resoluta ser frequentemente intolerável. A política, por conta da sua resiliência, que impede que a reforma agrária seja riscada da agenda do Estado-Nação burguês sem deixar rastros. A economia porque é precisamente o campesinato que está conseguindo alcançar patamares de produtividade numa lógica inversa à da agricultura convencional, minimizando inputs externos e maximizando insumos internos. (PLOEG, 2009). 
Em tempos de crise profunda, produto do paradigma técnico que em longo prazo não se sustenta, pela destruição das bases que a agricultura não pode prescindir, como solo fértil, água e biodiversidade, são exatamente os camponeses que potencial ou efetivamente possuem conhecimentos e práticas capazes de perpetuar a produção com parcimônia ambiental e compatibilização social, respostas que cada vez mais serão decisivas para a humanidade.

Isso não significa, em absoluto, a sua idealização, porque se tem claro que eles são parte do modo capitalista de produção tanto quanto as demais classes que parecem estar a salvo da seara desconceitualizante. A esse respeito, Bartra (2008) é preciso na crítica à dualidade: não há redenção possível às formas de opressão externas ao modo capitalista de produção, porque não há sociedades puras, ainda não contaminadas pelos seus males. Por isso, distingue o viver sob a lógica capitalista, para ele universal na atualidade, e render-se a seus preceitos, colocando precisamente nesse paradoxo os elementos que possibilitam sua superação. Trata-se, pois, de uma leitura que subverte a visão fatalista embutida na concepção de que o capitalismo é uma ordem monolítica, sem fraturas. Essa é a advertência.

La paradoja es que estando dentro também estamos afuera, pues 'vivir en y con el capitalismo puede ser algo más que vivir por y para él'. [...] todos hasta agora - son socialidades contradictorias que a la vez que subyugam incuban las fuerzas que habrán de transcenderlos: energias más o menos poderosas pero siempre presentes que los niegan quedo pero diário, que los subvierten de a poquito todo el tiempo. (BARTRA, 2008, p. 25, grifos do autor). 


\section{REFERÊNCIAS}

AKRAM-LODHI, H.; BORRAS JR, S.; KAY, C. Land,poverty and livelihoods in an era of globalisation. London:Routledge, 2007.

ALTIERI, M. A.; MANUEL, V. M. The agroecological revolution in Latin America: rescuing nature, ensuring food sovereignty and empowering peasants. In: The Journal of Peasant Studies, v. 38, n.3, p. 587-612, jul. 2011.

ANDRADE, M. C. Geopolítica do Brasil. São Paulo: Ática, 1989.

ARENDT, H. Sobre a violencia. Rio de Janeiro: Civilizacao Brasileira, 2009.

BARTRA, A. El hombre de hierro: los limites socialies y naturales del capital. México: UNAM-ITACA, 2008.

BERNSTEIN, H. Dinámicas de clase y transformación agraria. México: Universidad Autónoma de Zacatecas, 2012.

BORRAS, S. M. et al. Towards a better understanding of global land grabbing: an editorial introduction. The Journal of Peasant Studies, v. 38, n. 2, 209-216, mar. 2011.

BORRAS, S. M. Jr ; FRANCO; J. C. Global land grabbing and trajectories of agrarian change: a preliminary analysis. Journal of Agrarian Change, v. 12, n. 1, p. 3459, jan. 2012.

FAO. Políticas de mercado de trabajo y pobreza en America Latina. Tomo 1. FAO/ CEPAL: 2012. Disponível em:

http://www.fao.org/alc/file/media/pubs/2012/politicas_mercado_trabajo_i.pdf. Acesso em: 26 set. 2012.

CHANG, H. J. Chutando a escada. São Paulo: Unesp, 2004.

CONAB. Companhia Nacional de Abastecimento. Área plantada no Brasil. Acompanhamento da safra brasileira de grãos 2011/2012, décimo segundo levantamento, setembro de 2012. CONAB: Brasília, 2012. Disponível em: <http://www.conab.gov.br/OlalaCMS/uploads/arquivos/12_09_06_09_18_33_b oletim_graos_-_setembro_2012.pdf >. Acesso em: 20 set. 2012. 
COSTA, W. M. Geografia Política e Geopolítica. 2. ed. Brasil: Edusp, 2008.

CHESNAIS, F. As raízes da crise econômica mundial. O olho da História, n. 18, jul. 2012.

CYPHER, J. Teorias del desarrollo: una perspectiva economica critica. In:

VELTMEYER, Henry (coord.). Herramientas para el cambio: manual para los estudios críticos del desarrollo. Bolívia, Universidad Mayor de San Andrés: Plural Editores, 2011.

ELLIS, F. Peasant economics: farm households and agrarian development. UK: Cambridge University Press, 1988.

GASQUES J. G; BASTOS, E. T.; VALDES, C. Preços da terra no Brasil. Congresso da Sociedade Brasileira de Economia, Administração e Sociologia Rural, 46. Rio Branco: SOBER, 2008.

HARVEY, D. A produção capitalista do espaço. São Paulo: Annablume, 2005.

HARVEY, D. O novo imperialismo. São Paulo: Loyola, 2004.

HUIZER, G. Peasant mobilization for land reform: historical case studies and theoretical considerations. In: GHIMIRE, Krishna B. Land reforma and peasant livelihoods. Great Britain: ITDC Plublishing, 2001.

KAUTSKY, K. A questão agrária. 3. ed. São Paulo: Proposta, 1980.

KAY, C. Development strategies and rural development: exploring synergies, eradicating poverty. The Journal of Peasant Studies, v. 36, n. 1, p. 103 -137, Jan. 2009.

KAY, C. Pobreza rural em América Latina y estratégias de desarrollo, In: Revista Mexicana de Sociologia, México, n. 69 (1), p. 69-108, 2007

LENIN, V. I. Capitalismo e agricultura nos Estados Unidos da América. São Paulo: Brasil Debates, 1980.

MARX, K. O capital, livro 3, v. 6. Rio de Janeiro: Civilização Brasileira, 1974. 
MAZOYER, M.; ROUDART, L. História das agriculturas no mundo: do neolítico à crise contemporânea. São Paulo: UNESP: 2010.

OLIVEIRA, A. U. A questão da aquisição de terras por estrangeiros no Brasil: um retorno aos dossiês. Agrária, São Paulo, n.12, p.3-113, 2010.

PLOEG, J. D.V.D. Camponeses e impérios alimentares: lutas por autonomia e sustentabilidade na era da globalização. Porto Alegre: UFRGS, 2008.

PORTES, A.; HOFFMAN, K. Las estructuras de clase em América Latina: composición y cambios durante la época neoliberal. Cadernos CEPAL, Nações Unidas, Série Políticas Sociales, n. 68, p. 1-51, 2003.

SBPC/ABC. O Código Florestal e a Ciência: contribuições para o diálogo. Sociedade Brasileira para o Progresso da Ciência/Academia Brasileira de Ciências: São Paulo, 2011.

SHANIN, T. Questões camponesas. In: PAULINO, E.T.; FABRINI, J. E. Campesinato e territórios em disputa. São Paulo: Expressão Popular, 2008. p. 139-160.

TRETEAULT, D. V. Conflitos socioambientales en México. Observatorio del Desarrollo, México, n.1, p. 8-9, jan-abr. 2012.

USDA. United States Department of Agriculture. National Agricultural Statistics Service: land values 2011. Disponível em: http://usda01.library.cornell.edu/usda/current/AgriLandVa/AgriLandVa-08-042011.pdf. Acesso em: 18 ago 2012.

VELTMEYER, H. Estudios agrarios críticos: Economia Politica de transformación agrária. Curso de Maestria. UNESP, Presidente Prudente, ago. set. 2011a. (informação verbal - aula).

VELTMEYER, H. Un sinopsis de la idea de desarrollo. In: Migración y Desarrollo, $\mathrm{n}$. 14, p. 9-34, 1. Sem. 2011 b.

PARPART, J.; VELTMEYER, H. Estudios Críticos del desarrollo: la evolución de una idea. Herramientas para el cambio: manual para los estudios críticos del desarrollo. Bolívia, Universidad Mayor de San Andrés: Plural Editores, 2011. 